\title{
Quality of Recovery after Anesthesia: Validation of the Portuguese Version of the "Quality of Recovery 15" Questionnaire
}

\author{
Qualidade de Recuperação após Anestesia: Validação da Versão Portuguesa do \\ Questionário "Quality of Recovery 15"
}

Ana Carolina SÁ ${ }^{1}$, Gabriela SOUSA ${ }^{1}$, Alice SANTOS ${ }^{1}$, Cristina SANTOS ${ }^{2}$, Fernando José ABELHA $\triangle^{1,3}$

Acta Med Port 2015 Sep-Oct;28(5):567-574

ABSTRACT

Background: The "Quality of Recovery 15" questionnaire is used for the study of quality recovery after anesthesia. The aim of this study was to validate the Portuguese version of "Quality of Recovery 15" questionnaire.

Material and Methods: After study approval by the institutional ethics committee, an observational and cohort prospective study was conducted on patients scheduled for elective surgery from June to August 2013. The "Quality of Recovery 15" questionnaire was translated in accordance with available guidelines. The "Quality of Recovery 15" Portuguese version was used before surgery (T0) and $24 \mathrm{~h}$ postoperatively (T1) on 170 patients. Patients who were unable to give informed consent or had cognitive impairment were excluded. Poor quality of recovery was defined for "Quality of Recovery 15" score at T1 lower than the mean "Quality of Recovery 15 " score minus 1 standard deviation. Reliability and observer disagreement was assessed using interclass correlation. Non-parametric tests were used for comparisons.

Results: There was a negative correlation between "Quality of Recovery 15" score and time spent in the postanesthesia care $(\rho=-0.264, p=0.004)$ and length of hospital stay $(\rho=-0.274, p=0.004)$. Thirty-two patients $(19 \%)$ had poor quality of recovery. Patients with poor quality of recovery had more frequently diabetes mellitus and hypertension and they were taking antidepressants drugs more frequently. Patients with poor quality of recovery were more frequently submitted to combined anesthesia and less frequently to general anesthesia and locoregional anesthesia $(p=0.008)$. The questionnaire had a good internal consistency and test-retest reliability was good.

Discussion: The Portuguese version of the "Quality of Recovery 15" showed a good correlation with the original.

Conclusion: This questionnaire appears to be an accurate and reliable assessment for quality of recovery.

Keywords: Anesthesia Recovery Period; Patient Satisfaction; Portugal; Questionnaires.

\section{RESUMO}

Introdução: O questionário "Quality of Recovery 15" tem sido utilizado para o estudo da qualidade de recuperação após anestesia. O objetivo deste estudo foi validar a versão Portuguesa do questionário "Quality of Recovery 15".

Material e Métodos: Após aprovação pela Comissão de Ética institucional, foi realizado um estudo de coorte prospectivo em doentes submetidos a cirurgia eletiva de junho a agosto de 2013. A versão portuguesa do "Quality of Recovery 15 " foi aplicada antes da cirurgia (T0) e 24 h após a cirurgia (T1) em 170 doentes. Os doentes incapazes de dar consentimento informado ou com comprometimento cognitivo foram excluídos. Má qualidade de recuperação foi definida para pontuações de "Quality of Recovery 15 ” em T1 inferiores à média das pontuações de "Quality of Recovery 15" menos 1 desvio padrão. Confiabilidade e discordância entre observadores foram avaliadas por meio da correlação intraclasse. Testes não-paramétricos foram utilizados para comparações.

Resultados: Observou-se uma correlação negativa entre pontuações de "Quality of Recovery 15" e tempo de internamento na Unidade Pós-Anestésica $(\rho=-0,264, p=0,004)$ e tempo de internamento hospitalar $(\rho=-0,274, p=0,004)$. Trinta e dois doentes (19\%) tiveram má qualidade de recuperação. Os doentes com má qualidade de recuperação tinham mais frequentemente diabetes mellitus e hipertensão arterial e estavam medicados com antidepressivos com mais frequência. Os doentes com má qualidade de recuperação foram mais frequentemente submetidos a anestesia combinada e menos frequente a anestesia geral e locorregional $(p=0,008)$. $O$ questionário teve boa consistência interna; a confiabilidade do teste-reteste foi boa.

Discussão: A versão portuguesa do "Quality of Recovery 15" mostrou boa correlação com a versão original.

Conclusão: Este questionário parece ser uma avaliação precisa e confiável para a qualidade de recuperação.

Palavras-chave: Período de Recuperação da Anestesia; Portugal; Questionários; Satisfação do Doente.

\section{INTRODUCTION}

Quality of recovery (QoR) after anesthesia is an important measure of the early postoperative health status of patients. ${ }^{1}$ The first studies to assess recovery after anesthesia and surgery only have measured physiological endpoints, recovery times and incidence of major morbidity and mortality and mostly ignore quality of recovery from the patient's perspective. Other than the anesthesia and surgery success in an objective and medical perspective, it is ever more relevant how the patient reacts and adapts to the surgical intervention and how it reflects into his/her physical and mental health in a more subjective way. Quality of postoperative recovery also has been focused around patient-oriented endpoints what has raised new interest because measurements and targets can be emphasized and changes can be observed and measured. Therefore, a variety of measurement tools have been developed..$^{1-5}$

1.Department of Anesthesiology. Centro Hospitalar São João. Porto. Portugal.

2. Health Information and Decision Sciences Department. Faculdade de Medicina. Universidade do Porto. Porto. Portugal.

3. Department of Anesthesiology and Perioperative Medicine. Faculdade de Medicina. Universidade do Porto. Porto. Portugal.

$\square$ Autor correspondente: Fernando José Abelha. fernando.abelha@gmail.com

Recebido: 27 de Dezembro de 2014 - Aceite: 13 de Abril de 2015 | Copyright @ Ordem dos Médicos 2015 
In the late nineties, Myles et al developed the QoR-score instrument, consisting in a brief nine-item questionnaire and one year later a more comprehensive 40 -item score. ${ }^{1,2}$

The QoR-40 is a global measure of QoR, it is usually completed under 10 minutes and demonstrated superior validity and reliability compared with the QoR Score. ${ }^{2}$ The QoR-40 since then became the most widely reported measure of patient-assessed quality of recovery after surgery. ${ }^{6,7}$

A short version of the 40-question QoR-40 was later developed and tested. The short version consisted on 15 questions. It performed well in all dimensions and took only about 2.5 minutes to complete. When compared with the QoR-40, the QoR-15 provides an equally extensive, yet less time consuming evaluation of a patient's QoR after anesthesia and surgery. ${ }^{9}$

The QoR-15 was already validated using a variety of endpoints and its ability to measure QoR was demonstrated previously. ${ }^{9}$

The QoR-15 provides a valid and easy-to-use method of measuring the quality of a patient's postoperative recovery and is a valuable outcome measure for assessing the impact of changes in health care delivery. ${ }^{9}$ Therefore, the QoR-15 could be an important mean to evaluate the quality of recovery after anesthesia and surgery, which may provide information to improve the quality of anesthesia and surgery.

The aim of this study was to translate, retranslate and validate the QoR-15 questionnaire for use in clinical research and routine use in Portuguese speaking Portuguese Post Anesthesia Care Unit (PACU) settings.

\section{MATERIAL AND METHODS}

\section{Subjects and settings}

The institutional review board of our hospital approved the study and informed consent was obtained preoperatively from each study patient. This prospective study was carried out in the PACU at the Hospital São João, an 1100bed community teaching hospital in Porto. Portugal. All adult post-operative patients admitted at the PACU who underwent a group of 8 surgical standard elective surgeries (thyroidectomy, thoracotomy, amputation of inferior limb, cholecystectomy, herniorrhaphy, hysterectomy, mastectomy and hip or knee arthroplasty), between 16 June 2013 and 31 August 2013, were eligible to the study.

Patients who were unable to give informed consent, had cognitive impairment (Mini-Mental State Examination < 24), non-Portuguese speaking. distress or any severe preexisting medical condition that limited objective assessment after operation or the presence of any life threatening postoperative complication were excluded from the study.

\section{The QoR-15 questionnaire}

The QoR-15 questionnaire has 15 questions that assess patient-reported quality of a patient's postoperative recovery using a 11-point numerical rating scale that leads to a minimum score of 0 (poor recovery) and a maximum score of 150 (excellent recovery).

\section{Testing procedure}

Translation and back-translation of the QoR-15 questionnaire: After permission from Stark et al, translation of the instrument was done according to proposed guidelines and model of principles for good practice in the translation process suggested by the Translation and Cultural Adaptation group. ${ }^{11}$

The translation process is described as follows: preparation, forward translation, reconciliation, back translation, back translation review, harmonization, cognitive debriefing, review of cognitive debriefing results and finalization and proof reading.

Preparation: Permission to use the QoR-15 questionnaire to the author developer (Stark PA) was asked and accepted.

Forward translation/reconciliation: A group of experienced intensive care nurses, the author and a professional translator translated the source text of the English version of the QoR-15 questionnaire to Portuguese. This was carried out independently and then they met to compare their translations.

Reconciliation: Differences from multiple independent translations were discussed and an agreement was set on the final translated version.

Back translation: The final Portuguese version was given to a professional translator for retranslation to English without knowledge of the original version.

Back translation review: The group who firstly translated the original version compared the retranslated version with the original and discrepancies were identified and corrected.

Harmonization: Comparison of back translation with the original instrument to highlight discrepancies between the original and its derivative.

Cognitive debriefing: Ten experienced nurses specialized in intensive care were asked to read and examine the translated version to detect any unclear words, concepts or elements that they were unable to understand.

Review of cognitive debriefing results and finalization: The findings of the debriefing process were incorporated to improve the performance of the translation. Applicability was evaluated through its application in PACU patients.

Data collection: Informed consent was obtained preoperatively for every patient. Data collection occurred at preoperatively (T0) and 24 hours postoperatively (T1). Patient characteristics, including age, gender, education, ASA physical status, body mass index (BMI), medical history and previous medication were recorded.

Anesthesia was conducted according to the attending anaesthetist's preference. Details of the anaesthetic technique, administered drugs, monitoring and duration of anesthesia were collected from the anaesthetic record. Surgery type and duration were obtained from the anesthesia-dedicated software $\left(\mathrm{PIClS}^{\circledR}\right)$. Surgery was 
considered to be long if surgical time was longer than one hundred fifty minutes. Type of anesthesia was categorized in general, combined (the combination of general and locoregional) and locoregional.

Visual Analogical Scale for pain assessment and PACU length of stay were collected in the PACU setting.

Baseline QoR was recorded before surgery (T0) and re-evaluated 24 hours after surgery (T1) using the QoR-15 Portuguese version (Appendix 1).

In order to assess the reliability and observer disagreement, the QoR-15 Portuguese version was applied by different and independent observers to 24 patients. 24 hours after surgery corresponding to T1 observations. Time taken for patients to complete the 15-item Questionnaire was measured in this subset of patients.

Poor quality of recovery (PQR) was defined for patients with a QoR-15 score lower to the mean QoR-15 score at T1, minus 1 standard deviations.

\section{Statistical methods}

Normality was tested using the One-Sample KolmogorovSmirnov test. Normally distributed data were summarised using mean and standard deviation and skewed data were summarised using median and interquartile range (IQR). Qualitative data were registered as frequency and percentage. Correlations were measured using Pearson ( $r$ ) or Spearman rank $(\rho)$ correlation coefficients.

For type of surgery analyses a Bonferroni correction was used to counteract multiple comparisons.

To compare the QoR-15 scores between groups of each variable Mann-Whitney $U$ test was used. To compare the QoR-15 scores items after and before surgery Wilcoxon signed rank test was used. To compare demographic and clinical data between patients with and without PQR Mannwhiney $U$ test. Chi-square test or Fisher exact test were used as appropriate.

Differences were considered statistically significant when $p$ was $<0.05$.

The reliability was assessed using Intraclass Correlation Coefficient (ICC) and observer disagreement was assessed using Information Based Measure of Disagreement (IBMD). ${ }^{12}$ The internal consistency of the QoR-15 T was also evaluated by using Cronbach's alpha $(\alpha)$ for the global QoR-15. A Cronbach's alpha coefficient of 0.70 to 0.95 was considered to be acceptable. ${ }^{12.13}$

Analysis was completed using the Statistical Package for Social Sciences (SPSS Inc. Chicago. IL) version 21.0.

\section{RESULTS}

Agreement regarding the translation and structure for the Portuguese proposed QoR-15 was achieved. No ambiguity was found in the cognitive debriefing. Approval of the back-translated version was obtained from the original scale's authors.

The Portuguese version of QoR-15 was applied to 170 patients consecutively admitted in the PACU.

Table 1 - Median QoR-15 scores according to the studied variables before and after surgery for categorical variables

\begin{tabular}{|c|c|c|c|c|}
\hline Variable & $\begin{array}{c}\text { QoR-15 } \\
\text { Before surgery }\end{array}$ & $\boldsymbol{p}^{*}$ & $\begin{array}{c}\text { QoR-15 } \\
\text { After surgery }\end{array}$ & $\boldsymbol{p}^{*}$ \\
\hline \multicolumn{5}{|l|}{ Age } \\
\hline$<65$ vs $\geq 65$ & 136 vs 117 & $<0.001$ & 126 vs 115 & 0.682 \\
\hline \multicolumn{5}{|l|}{ Gender } \\
\hline Male vs female & 125 vs 132 & 0.033 & 114 vs 117 & 0.437 \\
\hline \multicolumn{5}{|l|}{ ASA physical status } \\
\hline I/II vs III/IV/V & 134 vs 119 & $<0.001$ & 119 vs 107 & 0.192 \\
\hline Hypertension (yes vs no) & 131 vs 134 & 0.035 & 115 vs 117 & 0.334 \\
\hline Diabetes mellitus (yes vs no) & 120 vs 134 & $<0.001$ & 112 vs 117 & 0.370 \\
\hline Peripheral vascular disease (yes vs no) & 103 vs 133 & $<0.001$ & 100 vs 119 & 0.035 \\
\hline COPD (yes vs no) & 115 vs 132 & 0.053 & 101 vs 118 & 0.047 \\
\hline Hyperlipidemia (yes vs no) & 123 vs 133 & 0.007 & 114 vs 119 & 0.143 \\
\hline Benzodiazepines therapy (yes vs no) & 127 vs 132 & 0.047 & 111 vs 118 & 262 \\
\hline Antidepressant therapy (yes vs no) & 124 vs 132 & 0.338 & 105 vs 118 & 0.078 \\
\hline \multicolumn{5}{|l|}{ Type of anesthesia (yes vs no) } \\
\hline General anesthesia & 132 vs 116 & 0.006 & 120 vs 101 & $<0.001$ \\
\hline Regional anesthesia & 107 vs 133 & $<0.001$ & 102 vs 119 & 0.001 \\
\hline Combined anesthesia & 133 vs 131 & 0.461 & 99 vs 118 & 0.048 \\
\hline Benzodiazepines pre-medication (yes vs no) & 122 vs 132 & 0.393 & 112 vs 118 & 0.122 \\
\hline Longer surgery (yes vs no) & 131 vs 138 & 0.045 & 117 vs 115 & 0.556 \\
\hline
\end{tabular}


Table 2 - Spearman rank $(\rho)$ correlation coefficients between QoR-15 scores and the studied variables, before and after surgery for numerical variables $(n=170)$

\begin{tabular}{|c|c|c|c|c|}
\hline Variable & $\begin{array}{c}\text { QoR-15 } \\
\text { Before surgery }\end{array}$ & $p$ & $\begin{array}{c}\text { QoR-15 } \\
\text { After surgery }\end{array}$ & p \\
\hline Age & -0.243 & 0.002 & -0.093 & 0.232 \\
\hline Body Mass Index $\left(\mathrm{Kg} / \mathrm{m}^{2}\right)$ & 0.126 & 0.108 & 0.140 & 0.073 \\
\hline \multicolumn{5}{|l|}{ Pain VAS } \\
\hline At PACU admission & -0.104 & 0.201 & -0.146 & 0.069 \\
\hline At PACU discharge & -0.073 & 0.389 & -0.074 & 0.382 \\
\hline Length of PACU stay (minutes) & -0.001 & 0.991 & -0.264 & 0.004 \\
\hline Length of Hospital stay (days) & -0.179 & 0.065 & -0.276 & 0.004 \\
\hline \multicolumn{5}{|c|}{ QoR-15: “Quality of Recovery 15" questionnaire; VAS: Visual Analogic Scale; PACU: Post Anesthesia Care Unit } \\
\hline $\begin{array}{l}\text { QoR-15 } \\
(n=146)\end{array}$ & & TO & T1 & $\boldsymbol{p}^{*}$ \\
\hline 1. Able to breathe easily & & $10(10-10)$ & $10(8-10)$ & 0.001 \\
\hline 2. Been able to enjoy food & & $10(9-10)$ & $8(4-10)$ & $<0.001$ \\
\hline 3. Feeling rested & & $8(5-10)$ & $8(6-10)$ & 0.753 \\
\hline 4. Have had a good sleep & & $9(5-10)$ & $8(5-9)$ & 0.015 \\
\hline 5. Able to look after personal toilet and hygiene unaided & & $10(10-10)$ & $8(2-10)$ & $<0.001$ \\
\hline 6. Able to communicate with family or friends & & $10(10-10)$ & $10(9-10)$ & $<0.001$ \\
\hline 7. Getting support from hospital doctors and nurses & & $10(10-10)$ & $10(9-10)$ & 0.001 \\
\hline 8. Able to return to work or usual home activities & & $10(7-10)$ & $7(2-9)$ & $<0.001$ \\
\hline 9. Feeling comfortable and in control & & $10(7-10)$ & $9(6-10)$ & 0.012 \\
\hline 10. Having a feeling of general well-being & & $9(6-10)$ & $8(5-10)$ & 0.013 \\
\hline 11. Moderate pain & & $10(7-10)$ & $5(3-9)$ & $<0.001$ \\
\hline 12. Severe pain & & $10(10-10)$ & $10(9-10)$ & 0.011 \\
\hline 13. Nausea or vomiting & & $10(10-10)$ & $10(9-10)$ & 0.001 \\
\hline 14. Feeling worried or anxious & & $5(3-9)$ & $8(5-10)$ & $<0.001$ \\
\hline 15. Feeling sad or depressed & & $8(5-10)$ & $10(5-10)$ & 0.015 \\
\hline Total & & $131(114-140)$ & $117(100-128)$ & $<0.001$ \\
\hline
\end{tabular}

Total QoR-15 score after surgery was significantly lower (median 117) than before surgery (median 131).

Median QoR-15 scores, according to the studied variables, before and after surgery, are summarized in Table 1. Correlations between each continuous variables and both QoR-15 before and after surgery are shown in Table 2.

After surgery, men and women had similar median QoR15 scores (114 vs $117 p=0.437$ ). Patients with COPD had lower scores after surgery (101 vs $118 p=0.047)$ and there were no significant relation between QoR-15 after surgery scores and patient age $(\rho=-0.093 p=0.232)$ or duration of surgery $(\rho=-0.142 p=0.076)$. Median scores for QoR15 after surgery were higher after general anesthesia (120 vs.101 $p<0.001)$ and lower after locoregional anesthesia (102 vs $119 p=0.001)$ and combined anesthesia (99 vs 118 $p=0.048)$.

There was a significant negative correlation between the QoR-15 after surgery and time spent in the PACU $(\rho=$ $-0.264 p=0.004)$ and duration of hospital stay $(\rho=-0.276$ $p=0.004$ ). Comparing scores on each item of QoR-15, all items changed scores 24 hours after surgery, except for 
item 'feeling rested' (Table 3).

Discriminant validity was determined by comparing patients who had PQR and patients who had not PQR. The median total QoR-15 score at T1 differed significantly between these groups (82 vs 122, $p<0.001)$.

Thirty-two patients (19\%) showed PQR 24h after surgery (Table 4). Patients who developed PQR had more frequently diabetes mellitus ( $38 \%$ vs $18 \% p=0.017$ ), arterial hypertension (66\% vs $45 \% p=0.035)$ and more frequently took medication like antidepressant drugs (28\% vs $9 \%$ $p=0.004)$. Patients submitted to combined anesthesia were more frequent in PQR group than in no PQR group (13\% vs $5 \%$ ); patients submitted to general anesthesia were less frequent in $\mathrm{PQR}$ group than in no $\mathrm{PQR}$ group
(53\% vs $80 \%$ ); patients with locoregional anesthesia were more frequent in PQR group than in no PQR group (28\% vs $24 \%$ ), this association between PQR or no PQR and type of anesthesia was significant $(p=0.008)$, age $(p=0.087)$ and gender $(p=0.102)$. ASA physical status $(0.180)$ or $\mathrm{BMI}(p=$ $0.565)$ were not different in patients with $P Q R$.

Patients with PQR had a longer length of stay at PACU $(p=0.351)$ but they had similar VAS scores for pain either at PACU admission or discharge $(p=0.297$ and $p=0.982$. respectively).

There was a significant association between the type of surgery and PQR ( $p<0.001)$ (Table 5).

Comparing patients submitted to each type of surgery with all other and after adjusting for Bonferroni correction

Table 4 - Demographic and clinical data between patients with and without PQR

\begin{tabular}{|c|c|c|c|}
\hline & $\begin{array}{l}\text { No } P Q R \\
(n=138)\end{array}$ & $\begin{array}{c}P Q R \\
(n=32)\end{array}$ & $p$ \\
\hline Age in years median (IQR) & $61(46-69)$ & $65(54-73)$ & $0.087^{\text {a) }}$ \\
\hline Gender n (\%) & & & $0.182^{b)}$ \\
\hline Male & $47(34)$ & $7(22)$ & \\
\hline Female & $91(66)$ & $25(78)$ & \\
\hline ASA physical status n (\%) & & & $0.180^{\mathrm{b})}$ \\
\hline $\mathrm{I} / \mathrm{II}$ & $110(80)$ & $22(69)$ & \\
\hline III/IV & $28(20)$ & $10(31)$ & \\
\hline Body Mass Index in $\mathrm{Kg} / \mathrm{m} 2$ median (IQR) & $26(23-30)$ & $26(22-27)$ & $0.565^{\text {a) }}$ \\
\hline \multicolumn{4}{|l|}{ Comorbidities/Medication n (\%) } \\
\hline Hypertension & $62(45)$ & $21(66)$ & $0.035^{b)}$ \\
\hline Diabetes mellitus & $25(18)$ & $12(38)$ & $0.017^{\mathrm{b})}$ \\
\hline Peripheral vascular disease & $18(13)$ & $8(25)$ & $0.090^{b)}$ \\
\hline COPD & $7(5)$ & $3(9)$ & $0.284^{c)}$ \\
\hline Dyslipidemia & $55(32)$ & $19(11)$ & $0.267^{\mathrm{b})}$ \\
\hline Benzodiazepines therapy & $29(21)$ & $10(31)$ & $0.223^{b)}$ \\
\hline Antidepressant therapy & $13(9)$ & $9(28)$ & $0.004^{b)}$ \\
\hline Type of anesthesia n (\%) & & & $0.008^{b)}$ \\
\hline General & $110(80)$ & $17(53)$ & \\
\hline Combined & $7(5)$ & $4(13)$ & \\
\hline Loco regional & $21(15)$ & $11(34)$ & \\
\hline Benzodiazepines for pre-medication & $33(24)$ & $9(28)$ & $0.634^{b)}$ \\
\hline Duration of anesthesia (min.) median (IQR) & $120(90-150)$ & $122(86-226)$ & $0.494^{\text {a) }}$ \\
\hline Longer surgery $\mathrm{n}(\%)$ & $28(20)$ & $9(28)$ & $0.333^{\text {a) }}$ \\
\hline \multicolumn{4}{|l|}{ Pain VAS } \\
\hline At PACU admission & $0(0-4)$ & $0(0-6)$ & $0.361^{\text {a) }}$ \\
\hline At PACU discharge & $0(0-2)$ & $1(0-2)$ & $0.673^{a)}$ \\
\hline PACU length of stay (minutes) median (IQR) & $90(67-119)$ & $103(85-134)$ & $0.103^{\text {a) }}$ \\
\hline Hospital length of stay (days) median (IQR) & $4(2-6)$ & $6(4-21)$ & $0.002^{\text {a) }}$ \\
\hline
\end{tabular}


Table 5 - Type of surgery the patients underwent with and without PQR

\begin{tabular}{lcc}
\hline & $\begin{array}{c}\text { No PQR } \\
\mathbf{8 1 \%}\end{array}$ & p \\
\hline Type of surgery & & $<\mathbf{0 . 0 0 1}$ \\
Thoracotomy & $4(44)$ \\
Amputation & $10(56)$ \\
Hip or knee arthroplasty & $13(65)$ \\
Hysterectomy & $10(83)$ \\
Mastectomy & $34(87)$ \\
Cholecystectomy & $21(91)$ \\
Thyroidectomy & $23(92)$ \\
Herniorrhaphy & $23(96)$ \\
\hline
\end{tabular}

PQR: Poor quality of recovery

patients submitted to amputation showed more frequently PQR (PQR in $44 \%$ vs $56 \%$ patients $(p=0.003$ ) (Table 6$)$.

Twenty-four hours after surgery patients with $P Q R$ had lower total scores for QoR-15 and for all items except for item 'feeling worried or anxious' and 'feeling sad or depressed' while patients without PQR scores were also lower for total score and for all items except for items 'feeling rested', 'have had a good sleep', 'feeling comfortable and in control', 'having a feeling of general well-being' and 'severe pain'.

It was found a high reliability between observers, ICC of 0.986 with a confidence interval of $95 \%$ (0.967 - 0.994). The QoR-15 shown a lower observer disagreement IBMD $=0.04$ with a confidence interval of $95 \%(0.029$ -0.058), which confirmed the obtained ICC. Internal consistency was tested and a Cronbach's Alpha of 0.884 was obtained for the global QoR-15.

The mean time of assessment was 22 hours after surgery with a range of $15-29$ hours after surgery. The mean time taken to complete the postoperative QoR-15 questionnaire was $2.8 \pm 0.8$ (range $1-5$ ) minutes. The successful completion rate was $100 \%$.

\section{DISCUSSION}

The main findings of our study are as follows:

a) The Portuguese QoR-15 is a reliable and valid tool in detecting quality of postoperative recovery after anesthesia; b) there was a significant negative correlation between the QoR-15 and time spent in the post anesthesia care and in the hospital; c) QoR-15 scores were higher after general anesthesia; d) There was no relation between QoR-15 24 hours after anesthesia score and gender, patient's age or duration of surgery; d) patients submitted to amputation and thoracotomy showed worse QoR more frequently contrary to patients submitted to cholecystectomy, hysterectomy, herniorrhaphy, mastectomy. hip or knee arthroplasty and thyroidectomy; f) patients who developed PQR had more frequently diabetes mellitus and hypertension and more frequently took antidepressant drugs and were more frequently submitted to combined anesthesia and less frequently to general anesthesia; g) patients with $P Q R$
Table 6 - Type of surgery the patients underwent with and without PQR

\begin{tabular}{|c|c|c|}
\hline Type of surgery & $\begin{array}{l}P Q R \\
19 \%\end{array}$ & $p$ \\
\hline Thoracotomy & & 0.013 \\
\hline Yes & $5(56)$ & \\
\hline Non & $27(17)$ & \\
\hline Amputation & & 0.003 \\
\hline Yes & $8(44)$ & \\
\hline Non & $24(16)$ & \\
\hline Hip or knee arthroplasty & & 0.049 \\
\hline Yes & $7(35)$ & \\
\hline Non & $25(17)$ & \\
\hline Hysterectomy & & 0.600 \\
\hline Yes & $2(17)$ & \\
\hline Non & $30(19)$ & \\
\hline Mastectomy & & 0.275 \\
\hline Yes & $5(13)$ & \\
\hline Non & $27(21)$ & \\
\hline Cholecystectomy & & 0.145 \\
\hline Yes & $2(9)$ & \\
\hline Non & $30(20)$ & \\
\hline Thyroidectomy & & 0.106 \\
\hline Yes & $2(8)$ & \\
\hline Non & $30(21)$ & \\
\hline Herniorrhaphy & & 0.034 \\
\hline Yes & $1(4)$ & \\
\hline Non & $31(21)$ & \\
\hline
\end{tabular}

PQR: Poor quality of recovery

stayed longer in the hospital.

This study suggests that the Portuguese QoR-15 is a reliable and valid tool in detecting quality of postoperative recovery after anesthesia. In this study, we have followed the guidelines for translation and cultural adaptation of the ISPOR TCA task force. The translated QoR-15 underwent a full validation process before use according to the recommendations of the TCA task force. The QoR-15 was translated by a group of researchers and professional translators, which facilitated the preservation of the meaning of the words and concepts that were specific to the context of the postoperative period. All the investigators were enrolled in the processes of planning, baseline and education phases. The physicians observed all the patients and recorded the data collected. The reliability coefficient achieved for QoR-15 was excellent, thus indicating that this scale is a reliable instrument to evaluate quality of recovery. Mean time to complete the questionnaire was less than 3 minutes and successful completion rate was $100 \%$ what may indicate that the questionnaire had a high acceptability and feasibility indicating that was easily applied. 
Internal consistency was measured using Cronbach $\alpha$ and this coefficient was high and satisfied published recommendations $(0.70-0.90)$. These results were comparable to those obtained by the authors and indicate that the QoR-15 should provide reliable. ${ }^{14}$

For the prospective evaluation of the Portuguese version of QoR-15 we chose to study a broad range of surgeries to maximally test the performance of the QoR-15 and to demonstrate its utility in different settings. We selected eight surgical interventions in order to have a more consistent group of patients easily clustered to promote comparisons.

The translated version showed to be easy and practical for the regular day-to-day practice. Most patients were able to complete the questionnaire in less than $3 \mathrm{~min}$ and the successful completion rate was $100 \%$ what may indicate a good acceptability and feasibility of the QoR-15.

Opposite to related studies where women showed worse QoR, we didn't find a statistical significant relationship between gender and PQR. ${ }^{3,9,15}$ There was no correlation between age and PQR, which is consistent with other studies. ${ }^{9}$ This finding may be explained by the fact that elder patients tend to positively evaluate their health status and attribute less relevance to pain, nausea and vomiting. . $^{16,17}$

We could find a significant negative correlation between the QoR-15 and time spent in the hospital and in the post anesthesia care, such as found by Stark et al. ${ }^{9}$ However, unlike that same study and others, ${ }^{3,9,15}$ we didn't find a statistical significant relationship between gender and duration of surgery and PQR.

Scores for QoR-15 were higher after general anesthesia and lower after combined or locoregional anesthesia. Patients with PQR were more frequently submitted to combined anesthesia and less frequently to general anesthesia, although that may be a bias resulting from the fact that the majority of patients were submitted to general anesthesia alone.

Although a significant negative correlation between the QoR-15 after surgery and time spent in the PACU was found, we could not identify a negative association between PQR and the duration of time spent in the post anesthesia care unit. According to VAS for pain there were no differences in patients with PQR neither at admission nor at discharge, which may be indicative that pain alone is not the single factor affecting quality of recovery after anesthesia

Discriminative validity was determined by comparing patients who had significant poor quality of recovery with patients that did not have poor quality of recovery as statistically defined by the distribution of global total Qor-15 scores and the QoR-15 score, which differed significantly between these groups. With this strategy we noticed that two of the studied surgeries (thoracotomy and amputations) had more frequent $P Q R$ and that they corresponded to the more harmful surgeries. Again, we could not found that gender, age or duration of anesthesia was related to this group of patients with PQR. Patients with PQR had more frequently diabetes, hypertension or were on antidepressant therapy, which may be consistent with the fact that comorbidities may influence postoperative outcome and quality of recovery.

This study has several limitations. The time period of assessment was limited to 24 hours and therefore we may have missed patients presenting with late complications.

We did not take into account any postoperative complications such as delirium or pulmonary complications and we may have missed important known aspects relevant to quality of recovery after anesthesia. Other complications can be expected to have a major impact on QoR however our study did not have sufficient power to derive precise estimates of such factors. We recognize that the sample size limited the ability to detect small differences. We selected eight surgery types and excluded other surgical procedures, which reduced the sample size and the heterogeneity of the sample.

\section{CONCLUSION}

The Portuguese version of the QoR-15 showed a good correlation with the original version. The Portuguese QoR15 appears to be an accurate and reliable instrument for the study of QoR after anesthesia and surgery.

\section{PROTECTION OF HUMANS AND ANIMALS}

The authors declare that the procedures were followed according to the regulations established by the Clinical Research and Ethics Committee and to the Helsinki Declaration of the World Medical Association.

\section{DATA CONFIDENTIALITY}

The authors declare having followed the protocols in use at their working center regarding patient's data publication.

\section{CONFLICTS OF INTEREST}

The authors declare that there are no conflicts of interest.

\section{FUNDING SOURCES}

No subsidies or grants contributed to this work.

\section{CONFLICT OF INTEREST}

The authors did not use funds for the research and have no conflicts of interest.

\section{REFERENCES}

1. Myles PS, Hunt JO, Nightingale CE, Fletcher H, Beh T, Tanil D, et al. Development and psychometric testing of a quality of recovery score after general anesthesia and surgery in adults. Anesth. Analg. 1999;88:83-90.

2. Myles P, Williams D, Hendrata M, Anderson H, Weeks A. Patient satisfaction after anaesthesia and surgery: results of a prospective survey of 10.811 patients. Brit J Anaesth. 2000;84:6-10.

3. Myles P, Weitkamp B, Jones K, Melick J, Hensen S. Validity and reliability of a postoperative quality of recovery score: the QoR-40. Brit J Anaesth. 2000;84:11-5. 
4. Hogue SL, Reese PR, Colopy M, Fleisher LA, Tuman KJ, Twersky RS, et al. Assessing a tool to measure patient functional ability after outpatient surgery. Anesth Analg. 2000;91:97-106.

5. Royse CF, Newman S, Chung F, Stygall J, McKay RE, Boldt J, et al. Development and feasibility of a scale to assess postoperative recovery: the post-operative quality recovery scale. Anesthesiology. 2010;113:892-905.

6. Gornall BF, Myles PS, Smith CL, Burke JA, Leslie K, Pereira MJ, et al. Measurement of quality of recovery using the QoR-40: a quantitative systematic review. Br J Anaesth. 2013;111:161-9.

7. Gower ST, Quigg CA, Hunt JO, Wallace SK, Myles PS. A comparison of patient self-administered and investigator-administered measurement of quality of recovery using the QoR-40. Anaesth Intensive Care. 2006;34:634-8.

8. Leslie DL, Rosenheck RA. Benchmarking the quality of schizophrenia pharmacotherapy: a comparison of the Department of Veterans Affairs and the private sector. J Mental Health Policy Econ. 2003;6:113-21.

9. Stark PA, Myles PS, Burke JA. Development and psychometric evaluation of a postoperative quality of recovery score: the QoR-15. Anesthesiology. 2013;118:1332-40.

10. Postanesthesia Care Standarts. 2009. [Accessed 2014 Dec 15]. Available from: http://www.asahq.org/For-Members/StandardsGuidelines-and-Statements.aspx.
11. Wild D, Grove A, Martin M, Eremenco S, McElroy S, Verjee-Lorenz A, et al. Principles of Good Practice for the Translation and Cultural Adaptation Process for Patient-Reported Outcomes (PRO) Measures: Report of the ISPOR Task Force for Translation and Cultural Adaptation. Value Health. 2005;8:94-104.

12. Costa-Santos C, Antunes L, Souto A, Bernardes J. Assessment of disagreement: a new information-based approach. Ann Epidemiol. 2010;20:555-61.

13. Peterson RA. A meta-analysis of Cronbach's coefficient alpha. J Consumer Res. 1994:381-91.

14. McDowell I, Newell C, editors. Measuring health: a guide to rating scales and questionnaires. $3^{\text {rd }}$ edition. New York: Oxford University Press; 2006.

15. Buchanan $F$, Myles $P$, Cicuttini $F$. Effect of patient sex on general anaesthesia and recovery. Br J Anaesth. 2011;6:832-9.

16. Blanchard CG, Labrecque MS, Ruckdeschel JC, Blanchard EB. Physician behaviours, patient perceptions and patient characteristics as predictors of satisfaction of hospitalized adult cancer patients. Cancer. 1990;65:186-92.

17. Hall JA, Dornan MC. Patient sociodemographic characteristics as predictors of satisfaction with medical care: a meta-analysis. Soc Sci Med. 1990;30:811-8. 


\section{Quality of Recovery after Anesthesia: Validation of the Portuguese Version of the "Quality of Recovery 15" Questionnaire}

Acta Med Port 2015:28:567-574

Publicado pela Acta Médica Portuguesa, a Revista Científica da Ordem dos Médicos

Av. Almirante Gago Coutinho, 151

1749-084 Lisboa, Portugal.

Tel: +351218428 215

E-mail: submissao@actamedicaportuguesa.com

www.actamedicaportuguesa.com

ISSN:0870-399X | e-ISSN: 1646-0758

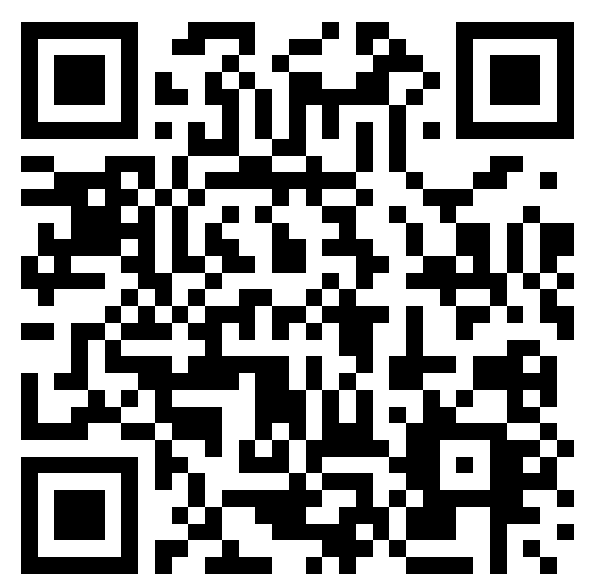

